\title{
A NOVEL THIN FILM COMPOSITE REVERSE OSMOSIS MEMBRANE MODIFIED BY IONIC LIQUID
}

\author{
H. Raval ${ }^{1 *}$, B. Mehta ${ }^{1}$, R. Joshi ${ }^{1}$ and A. Kumar ${ }^{1}$ \\ ${ }^{1}$ Reverse Osmosis Division, CSIR-Central Salt and Marine Chemicals Research Institute (CSIR-CSMCRI), Council of Scientific \& \\ Industrial Research (CSIR), Gijubhai Badheka Marg, Bhavnagar- 364 002, Gujarat INDIA.
}

(Submitted: October 18, 2017 ; Revised: January 14, 2018 ; Accepted: January 25, 2018)

\begin{abstract}
Thin Film Composite Reverse Osmosis (TFC RO) membranes have undergone significant changes since inception; particularly the top polyamide layer has been tuned for optimal performance. The present paper demonstrates the novel approach to alter the polyamide membrane performance by subjecting it to ionic liquids. Ionic liquids 1-Butyl-3-Methylimidazolium Chloride [BMIM][Cl], 1-Methyl-3-Octylimidazolium Chloride $\left[\mathrm{C}_{8} \mathrm{MIM}\right][\mathrm{Cl}]$ and 1-Butyl-3-Methylimidazolium Bromide [BMIM][Br] were used to alter the membrane performance. About a $6.5 \%$ increase in $\mathrm{MgSO}_{4}$ rejection and about an $87 \%$ increase in water-flux were noted when the membrane was subjected to $3000 \mathrm{mg} / \mathrm{L}$ [BMIM] [Cl] after $2000 \mathrm{mg} / \mathrm{L}$ sodium hypochlorite each for 2 hours. Also, the decline in contact angle from $52.86^{\circ}$ to $43.12^{\circ}$ by this treatment demonstrated higher hydrophilicity. Atomic force microscope images showed a decline in surface roughness with the treatment. Scanning electron micrographs were taken to understand the changes in morphology of thin film composite reverse osmosis membranes with ionic liquid treatment. Attenuated total reflectance, infrared spectroscopy and nuclear magnetic resonance analysis were done to evaluate the changes in chemical structure and it was found that the treatment resulted in chemical structural modification of thin film composite reverse osmosis membranes with ionic liquid treatment.

Keywords: Thin Film Composite Reverse Osmosis membrane; Ionic liquid; Surface modification; [BMIM][Cl]; $\left[\mathrm{C}_{8} \mathrm{MIM}\right][\mathrm{Cl}]$.
\end{abstract}

\section{INTRODUCTION}

The process of reverse osmosis, which was first commercially developed in the mid-1960s, has undergone significant development since then (Glater, 1998). Reverse osmosis, as it is commonly known, is now used extensively in various separation processes, including brackish and sea water desalination. Concentration polarization is one of the major hindrances, which causes a reduction in salt rejection and flux in reverse osmosis thin film composite membranes (Tang et al., 2010). Concentration polarization refers to the gradual increase in concentration of non-permeating components near the surface of the membrane, effectively reducing its capacity for salt rejection and flux (Morao et al., 2008). The top layer of a reverse osmosis membrane is dense. The thickness of this layer is an important consideration in concentration polarization. Thinning the top layer of the membrane can weaken the effects of concentration polarization and thereby theoretically increase the water flux (Wang et al., 2009). Thin film composite reverse osmosis membranes are either cellulose acetate or polyamide membrane. However, the latter is widely used because of its higher operating $\mathrm{pH}$ range, wider temperature range, higher stability to biological attack and ease of surface modification (Petersen et al., 1993; El-Saied et al., 2003; Younos et

\footnotetext{
* Corresponding author: Email: hirenraval@csmcri.res.in , raval.hiren@rediffmail.com , Fax: +91-278- 2566970
} 
al., 2005; Wethern et al., 1995; Asano, 1998; Kulkarni et al., 1996).

Various experiments have been performed for surface modification of reverse osmosis membranes using different modifying agents. These include the use of sodium hypochlorite and polysaccharides like chitosan (Raval et al., 2016; Raval et al., 2017; Raval et al., 2015). Some toxic, corrosive, flammable or environmentally harmful agents such as concentrated sulfuric acid and hydrofluoric acid (Gilron et al., 2001; Belfer et al., 1998). Room Temperature Ionic Liquids [RTIL] are salts in the liquid state in which ions are poorly coordinated and they exist in the liquid state below $100^{\circ} \mathrm{C}$. Ionic liquids have recently gained popularity in use in various chemical applications owing to their unique properties. Ionic liquids are powerful solvents and find applications in decomposing polymers and as additives in nano-filtration and other membranes (Swatloski et al., 2002; Lua et al., 2009; Yung et al., 2010; Mohammad et al., 2015). However, the application of ionic liquid for surface modification of thin film composite reverse osmosis membranes is largely unknown (Schmidt et al., 2008).

This paper aims at using ionic liquids as surface modifiers for commercial thin film composite reverse osmosis membranes and explores their effect on membrane performance. From various different ionic liquids 1-Butyl-3-Methylimidazolium Chloride $[\mathrm{BMIM}][\mathrm{Cl}]$ was found to give optimum results. The surface modification of the polyamide layer by the ionic liquid $[\mathrm{BMIM}][\mathrm{Cl}]$ has been characterized to explain the change in performance.

\section{EXPERIMENTAL}

\section{Materials}

Commercial thin film composite reverse osmosis membrane was purchased from Hydraunatics, USA (CPA2). 1-Butyl-3-Methylimidazolium Chloride $[\mathrm{BMIM}][\mathrm{Cl}]$ ionic liquid (Molecular Weight $=174.67$ g/mol), 1- Butyl-3-Methylimidazolium Bromide [BMIM][Br] (Molecular Weight $=219.12 \mathrm{~g} / \mathrm{mol}$ ), 1-Methyl-3-Octylimidazolium Chloride [ $\left.\mathrm{C}_{8} \mathrm{MIM}\right][\mathrm{Cl}]$ (Molecular Weight $=230.78 \mathrm{~g} / \mathrm{mol}$ ) were purchased from Sigma - Aldrich Co. LLC. Sodium hypochlorite (Molecular Weight $=74.44 \mathrm{~g} / \mathrm{mol}$ ) was purchased as laboratory reagent with available chlorine of $4 \%$ - 6\% w/v from RFCL limited, New Delhi (India). Magnesium sulphate (divalent salt) was purchased from Tokyo Chemical Industry Co., LTD, Tokyo, Japan. The chemical structure of the polyamide layer of thin film composite reverse osmosis membranes is shown in Figure 1 (Rangarajan et al., 2011).

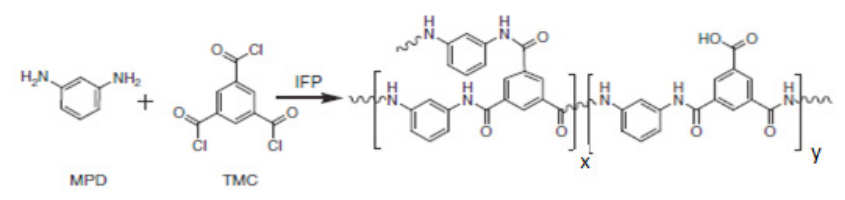

Figure 1. Interfacial polymerization reaction to form aromatic polyamide.

\section{Treatment of membrane with sodium hypochlorite and ionic liquid}

Polyamide thin film composite reverse osmosis membranes were cut into a strip of $10 \mathrm{~cm} \times 10 \mathrm{~cm}$, cleaned with deionized water. We stuck the membrane strip on a glass plate to ensure that only the top layer was subjected to treatment and the other components remained air tight and free of any chemical contact. We dipped the membrane into a $2000 \mathrm{mg} / \mathrm{L}$ solution of sodium hypochlorite for a period of 2 hours. Membrane was then taken out and once again thoroughly washed with deionized water and then cut into two strips each of $5 \mathrm{~cm} \times 10 \mathrm{~cm}$. One strip was immediately dipped into a solution of 1-Butyl-3Methylimidazolium Chloride [BMIM] [Cl] ionic liquid for 2 hours and the other strip was dipped into deionized water for the same period. A series of experiments were carried out in a similar fashion with varying concentration of 1-Butyl-3-Methylimidazolium Chloride [BMIM] $[\mathrm{Cl}]$ and other ionic liquids i.e. 1Butyl-3-Methylimidazolium Bromide [BMIM][Br] and 1-Methyl-3-Octylimidazolium Chloride [ $\left.\mathrm{C}_{8} \mathrm{MIM}\right]$ $[\mathrm{Cl}]$ as shown in Figure 2.

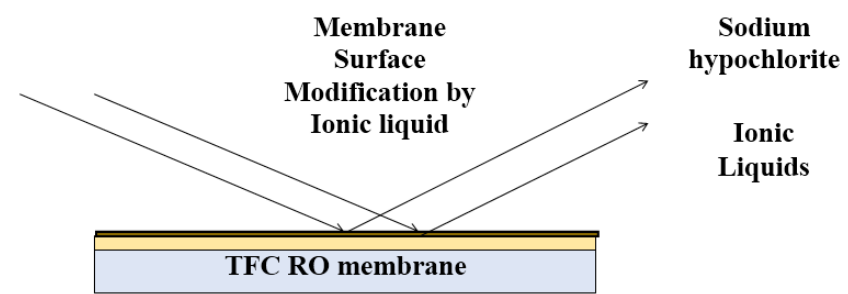

Figure 2. Schematic of membrane surface modification by ionic liquids.

\section{Membrane performance}

Experiments were carried out in a standard reverse osmosis experimentation kit. The modified membranes were subjected to magnesium sulfate solution of $4000 \mu \mathrm{S}$ in deionized water at $250 \mathrm{psig}$ pressure. The membranes were stabilized for 2 hours and then permeate was collected for 20 minute at 250 psig pressure to measure water-flux and conductivity as per the standard procedure.

\section{Membrane characterization}

We characterized the membranes by Scanning electron micrographs (SEM) to study the surface 
morphology, nuclear magnetic resonance (NMR) and attenuated total reflectance infrared spectroscopy (ATR-FTIR) and to understand the chemical structural modification, atomic force micrographs (AFM) to study the top surface roughness features and contact angle analysis for measuring surface hydrophilicity.

\section{RESULTS AND DISCUSSION}

\section{Divalent salt rejection}

Results as shown in Figure 3 and Figure 4 indicate that of the various different ionic liquids 1-Butyl-3Methylimidazolium Chloride [BMIM][Cl] gives the optimum results in terms of flux as well as divalent salt rejection. Also it can be inferred from Figure 4 and Table 1 that $3000 \mathrm{mg} / \mathrm{L}$ concentration of 1-Butyl-3Methylimidazolium Chloride [BMIM][Cl] gives 6.5\% increase in $\mathrm{MgSO}_{4}$ rejection and about $87 \%$ increase in water-flux as compared to virgin thin film composite reverse osmosis membranes and other concentrations of 1-Butyl-3-Methylimidazolium Chloride [BMIM][Cl].

It can be inferred from Table 1 that divalent salt rejection increases until $3000 \mathrm{mg} / \mathrm{L}$ 1-Butyl3-Methylimidazolium Chloride [BMIM][Cl] concentration and then decreases. Water flux also follows the similar trend. It can be deduced from the data in Table 1 that both water flux and magnesium

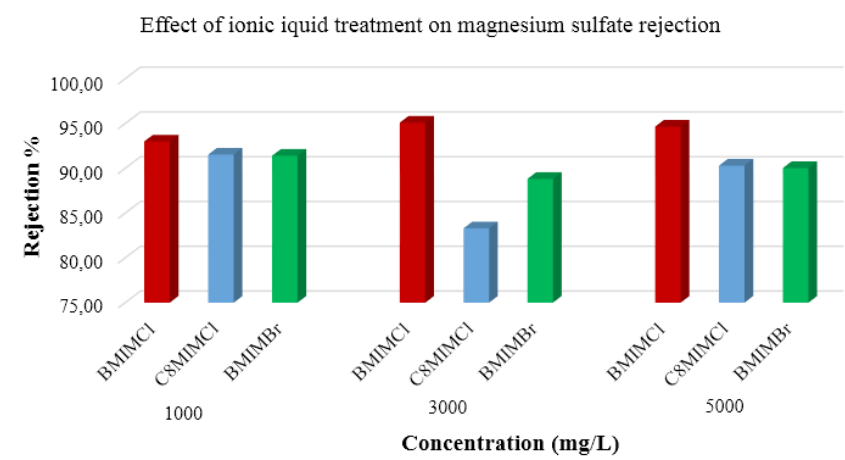

Figure 3. Divalent ion rejection comparison of various ionic liquids with varying concentrations.

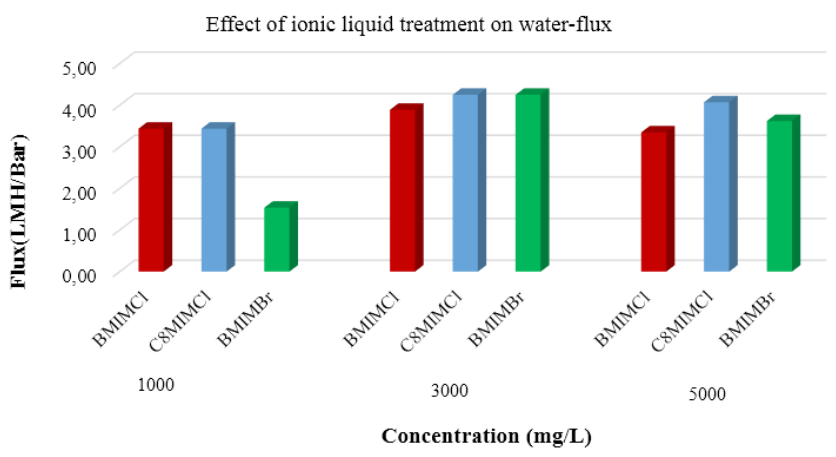

Figure 4. Water-flux comparison of different ionic liquids with varying concentrations.
Table 1. Membrane salt rejection and divalent rejection with different dosage of [BMIM][Cl] ionic liquid.

\begin{tabular}{ccc}
\hline Membrane & $\begin{array}{c}\text { Magnesium } \\
\text { sulfate } \\
\text { Rejection (\%) }\end{array}$ & $\begin{array}{c}\text { Flux } \\
\text { (LMH/bar) }\end{array}$ \\
\hline Thin Film Composite (TFC) & $89.30 \%$ & 2.08 \\
$500 \mathrm{mg} / \mathrm{L}$ Ionic Liquid & $84.98 \%$ & 3.16 \\
$1000 \mathrm{mg} /$ L Ionic Liquid & $93.00 \%$ & 3.44 \\
$3000 \mathrm{mg} /$ L Ionic Liquid & $95.10 \%$ & 3.89 \\
$4000 \mathrm{mg} /$ L Ionic Liquid & $94.91 \%$ & 3.62 \\
$5000 \mathrm{mg} /$ L Ionic Liquid & $94.66 \%$ & 3.34 \\
\hline
\end{tabular}

sulfate rejection increased for the ionic liquid 1-Butyl3-Methylimidazolium Chloride [BMIM] $[\mathrm{Cl}]$ treated membrane with $1000 \mathrm{mg} / \mathrm{L}$ to $5000 \mathrm{mg} / \mathrm{L}$ concentrations. For 1-Methyl-3-Octylimidazolium Chloride [ $\left.\mathrm{C}_{8} \mathrm{MIM}\right]$ $[\mathrm{Cl}]$ treated membranes, the water-flux is identical or more as compared to [BMIM] $[\mathrm{Cl}]$ treated membrane but magnesium sulfate rejection declined for all concentrations, as shown in Figures 3 and 4. For 1-Butyl-3-Methylimidazolium Bromide [BMIM][Br] treated membranes, magnesium sulfate rejection was lower as compared to 1-Butyl-3-Methylimidazolium Chloride $[\mathrm{BMIM}][\mathrm{Cl}]$ treated membrane.

\section{Contact angle of membranes}

Contact angles of membranes were measured using the drop shape analyser (DSA 100) provided by Krüss Optronic - Germany. The contact angle is a measure to study the hydrophilicity of the membrane, i.e., the contact angle of a water drop will decline with increased hydrophilicity. Contact angles for various membranes are mentioned in Table 2. It can be seen that the contact angle declines from $52.86^{\circ}$ to $43.12^{\circ}$ for $3000 \mathrm{mg} / \mathrm{L}$ 1-Butyl-3-Methylimidazolium Chloride [BMIM][Cl] as compared to virgin thin film composite reverse osmosis membrane. However, it increases further with higher concentration treatment, i.e., $4000 \mathrm{mg} / \mathrm{L}$ and $5000 \mathrm{mg} / \mathrm{L}$ of 1-Butyl-3-Methylimidazolium Chloride [BMIM][Cl].

Table 2. Membrane contact angle with different dosage of [BMIM][Cl] Ionic Liquid.

\begin{tabular}{cc}
\hline Membrane & $\begin{array}{c}\text { Contact } \\
\text { Angle }\left(^{\circ}\right)\end{array}$ \\
\hline Thin Film Composite $(\mathrm{TFC})$ & 52.86 \\
$500 \mathrm{mg} / \mathrm{L}[\mathrm{BMIM}][\mathrm{Cl}]$ & 57.00 \\
$1000 \mathrm{mg} / \mathrm{L}[\mathrm{BMIM}][\mathrm{Cl}]$ & 54.98 \\
$3000 \mathrm{mg} / \mathrm{L}[\mathrm{BMIM}][\mathrm{Cl}]$ & 43.12 \\
$4000 \mathrm{mg} / \mathrm{L}[\mathrm{BMIM}][\mathrm{Cl}]$ & 47.42 \\
$5000 \mathrm{mg} / \mathrm{L}[\mathrm{BMIM}][\mathrm{Cl}]$ & 48.60 \\
\hline
\end{tabular}

\section{Scanning Electron Micrographs (SEM)}

The morphology of the membrane modified by $3000 \mathrm{mg} / \mathrm{L}$ 1-Butyl-3-Methylimidazolium Chloride $[\mathrm{BMIM}][\mathrm{Cl}]$ was studied using field emission scanning 
electron microscope (JSM-7100F Japan). Figure 5 shows the SEM images.

Presence of ionic liquid can be observed in Figure 5 (b) \& (c). White spots can be clearly identified in Figure 5 (b) that shows the structural modification with ionic liquid treatment. The cross-section in Figure 5 (c) and (d) shows the thinning of the polyamide layer with the ionic liquid treatment. Top polyamide layer thickness was reduced to $60 \mathrm{~nm}$ as compared to average polyamide layer thickness, i.e., about $200 \mathrm{~nm}$ as reported in case of interfacial polymerization with hexane solvent (Ghosh et al., 2008). The decline in thickness of the membrane is because of interaction between polyamide and ionic liquid. Decline in thickness of the polyamide layer may be attributed to $\pi-\pi$ interactions of ionic liquid with polyamide.

\section{Atomic Force Microscope Images (AFM)}

The topography and surface roughness properties of the membrane modified by 1-Butyl-

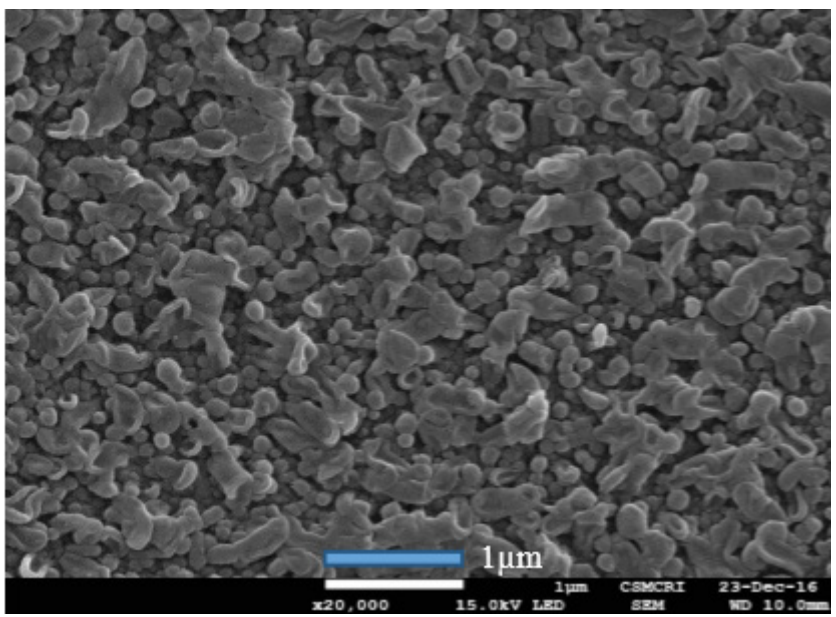

(a)

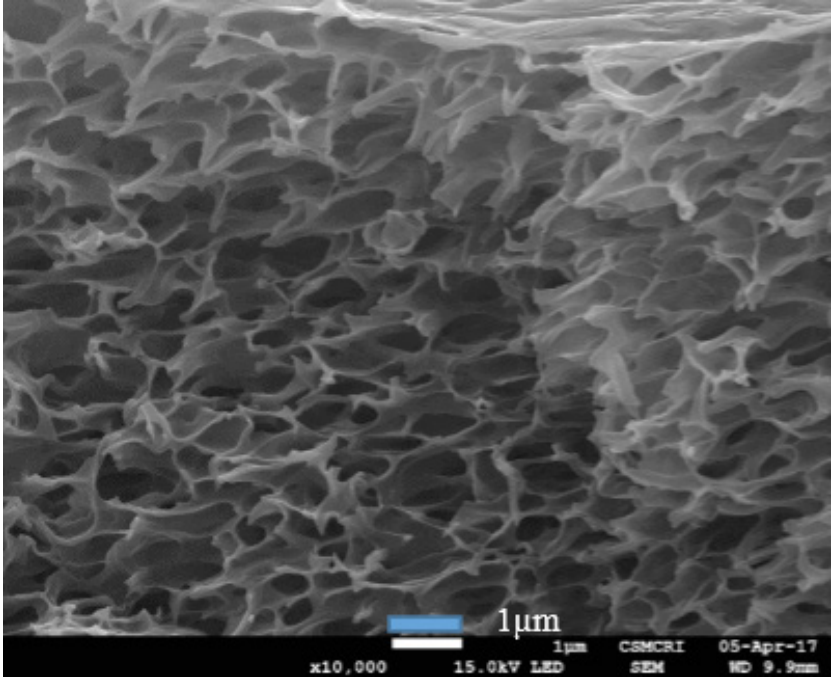

(c)
3-Methylimidazolium Chloride [BMIM][Cl] were measured using an atomic force microscope (NTEGRA Aura, NT-MDT Instruments, Russia). The images of virgin thin film composite membrane, and $500 \mathrm{mg} / \mathrm{L}, 3000 \mathrm{mg} / \mathrm{L}$ and $4000 \mathrm{mg} / \mathrm{L} \mathrm{1-Butyl-}$ 3-Methylimidazolium Chloride [BMIM][Cl] ionic liquid treated membranes are shown in Figure 6. The membrane with the highest water-flux and magnesium sulphate rejection, i.e., membrane treated with 3000 mg/L 1-Butyl-3-Methylimidazolium Chloride [BMIM] [Cl], showed the surface area ratio of $21.34 \%$ and roughness of $42.7 \mathrm{~nm}$ as shown in Table 3 . It shows the change in roughness with ionic liquid treatment.

\section{ATR - Fourier Transform Infrared spectroscopic analysis}

Attenuated total reflectance Fourier transform infrared spectroscopy (Spectrum GX FTIR Spectrometer, PerkinElmer, USA) was used to analyse the chemical structure of the virgin thin film composite

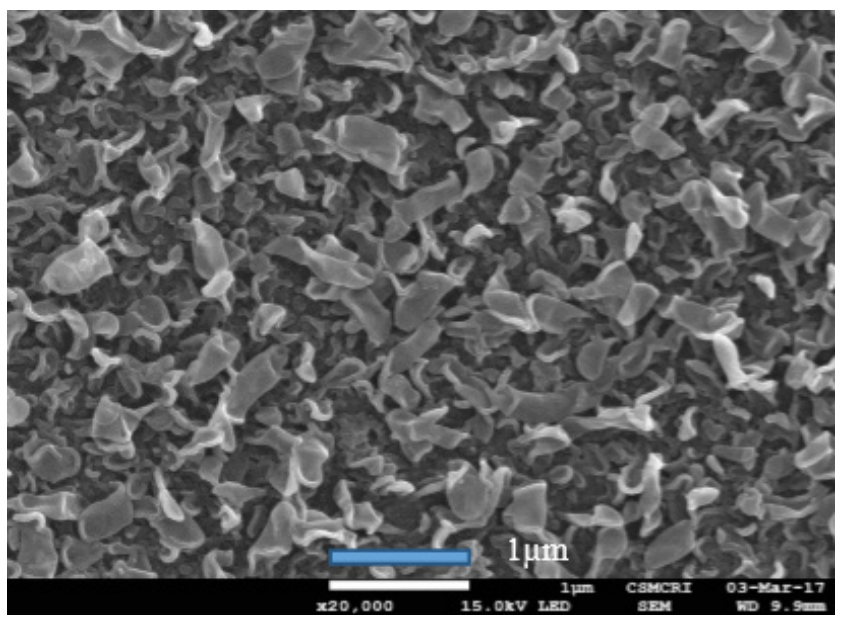

(b)

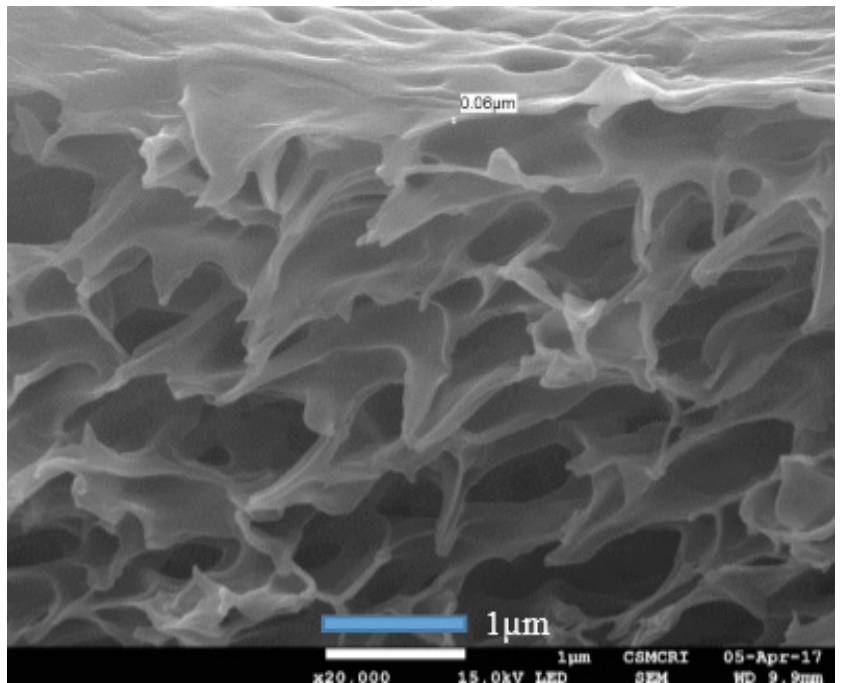

(d)

Figure 5. SEM images (a) virgin TFC membrane (b) modified membrane with $3000 \mathrm{mg} / \mathrm{L}$ [BMIM][Cl] ionic liquid (c) \& (d) Cross section of modified membrane with $3000 \mathrm{mg} / \mathrm{L}$ [BMIM][Cl] ionic liquid. 


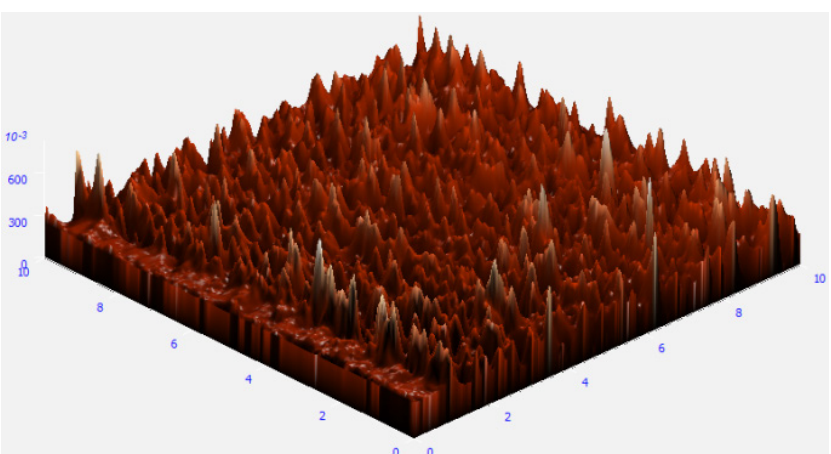

(a)

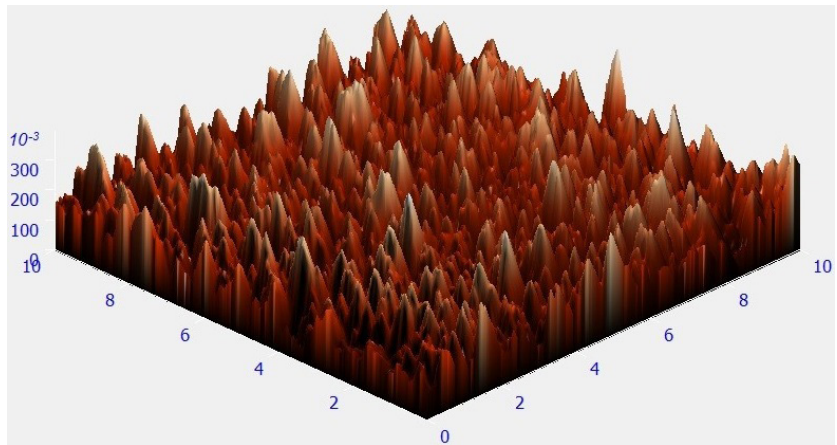

(c)

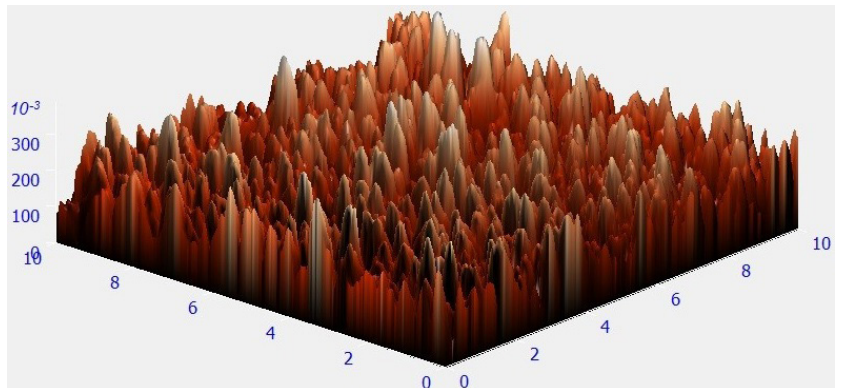

(b)

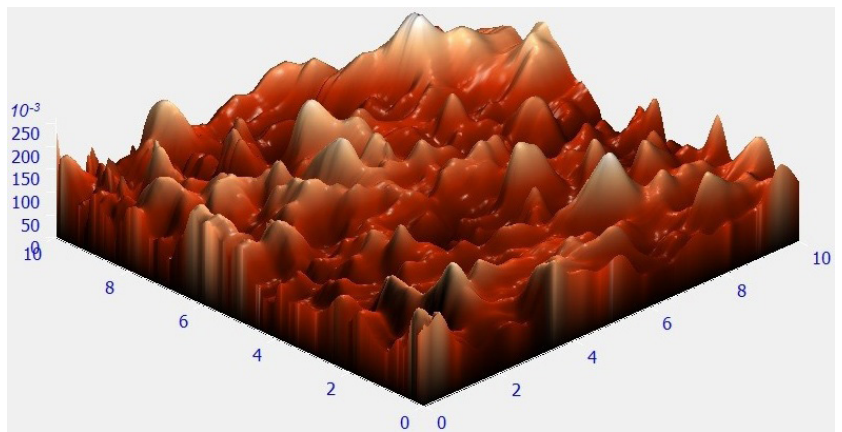

(d)

Figure 6. AFM images (a) TFC membrane (b) $500 \mathrm{mg} / \mathrm{L}$ [BMIM][Cl] (c) $3000 \mathrm{mg} / \mathrm{L}$ [BMIM][Cl] (d) $4000 \mathrm{mg} / \mathrm{L}$ $[\mathrm{BMIM}][\mathrm{Cl}]$.

Table 3. AFM data of TFC and $[\mathrm{BMIM}][\mathrm{Cl}]$ treated membranes.

\begin{tabular}{|c|c|c|c|c|}
\hline & TFC & $\begin{array}{c}500 \mathrm{mg} / \mathrm{L} \\
{[\mathrm{BMIM}][\mathrm{Cl}]}\end{array}$ & $\begin{array}{c}3000 \mathrm{mg} / \mathrm{L} \\
{[\mathrm{BMIM}][\mathrm{Cl}]}\end{array}$ & $\begin{array}{c}4000 \mathrm{mg} / \mathrm{L} \\
{[\mathrm{BMIM}][\mathrm{Cl}]}\end{array}$ \\
\hline Roughness Average, Sa (nm) & 64.7 & 44.2 & 42.7 & 29.3 \\
\hline Surface Area Ratio, Sdr & $21.94 \%$ & $29.44 \%$ & $21.34 \%$ & $18.89 \%$ \\
\hline
\end{tabular}

membrane and membrane modified with $3000 \mathrm{mg} / \mathrm{L}$ 1-Butyl-3-Methylimidazolium Chloride [BMIM] $[\mathrm{Cl}]$ ionic liquid. The ATR-FTIR spectra of both the membranes are shown in Figure 7. The identifiable peaks are mentioned in Table 4.

It can be seen from Figure 7 and Table 4 that the amide bond of polyamide layer has been modified by ionic liquid treatment. The peaks at $1635 \mathrm{~cm}^{-1}$ and 1589 $\mathrm{cm}^{-1}$ correspond to amide I and amide II, respectively. Amide I is comprised of $\mathrm{CO}$ stretching and amide II represents $\mathrm{NH}$ in-plane bending. It can be inferred that $\mathrm{CC}$ aromatic ring stretching has been affected by the treatment of ionic liquid on the TFC RO membrane. Ether and $\mathrm{C}=\mathrm{C}$ linkages have been modified by ionic liquid treatment of the polyamide layer. In this way, the chemical structural changes in the polyamide layer

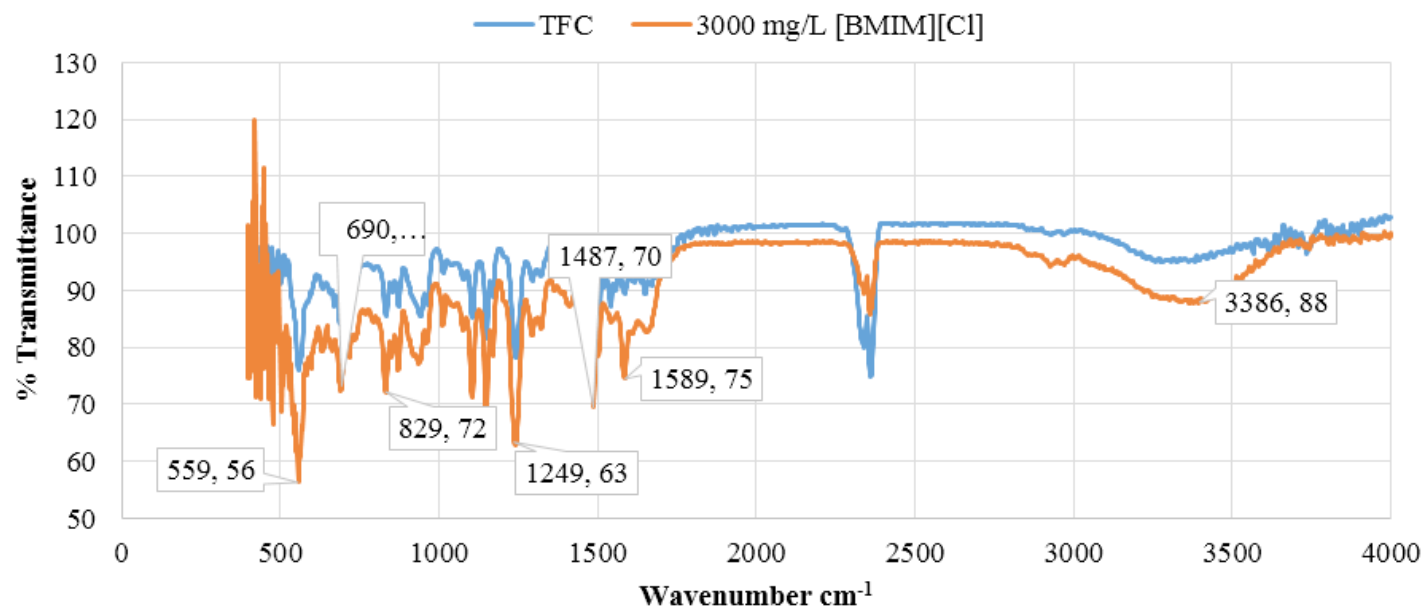

Figure 7. ATR FT-IR Spectra of virgin thin film composite and $3000 \mathrm{mg} / \mathrm{L}$ [BMIM][Cl]. 
Table 4. Peak identification of spectra of TFC and $3000 \mathrm{mg} / \mathrm{L}$ [BMIM] [Cl].

\begin{tabular}{ccccc}
\hline Sr. No. & $\begin{array}{c}\text { Wavenumber } \\
\mathbf{c m}^{-1}\end{array}$ & $\begin{array}{c}\text { Functional } \\
\text { Group }\end{array}$ & $\begin{array}{c}\text { Type of } \\
\text { Vibration }\end{array}$ & Intensity \\
\hline 1. & 559 & Alkyl halides & Stretch & Strong \\
3. & 829 & Alkenes $(=\mathrm{C}-\mathrm{H})$ & Bend & Strong \\
4. & 1249 & Ether $(\mathrm{C}-\mathrm{O})$ & Stretch & Strong \\
5. & 1487 & Aromatic compound (ring C=C $)$ & Stretch & Medium-Strong \\
6. & 1589 & Amide-II & Bend & Weak-Medium \\
7. & 1635 & Amide-I & Stretch & Weak-Medium \\
8. & 3386 & Stretch & Weak-Medium \\
\hline
\end{tabular}

are significant with ionic liquid treatment. To further investigate the modification in chemical structure, solid-state Nuclear Magnetic Resonance (NMR) spectra were taken for the virgin thin film composite reverse osmosis membrane and the $3000 \mathrm{mg} / \mathrm{L}$ 1-Butyl-3-Methylimidazolium Chloride [BMIM][Cl] ionic liquid treated membrane.

\section{Nuclear Magnetic Resonance spectroscopic analysis}

Nuclear magnetic resonance spectroscopy (Bruker Avance II $500 \mathrm{MHz}$ FT-NMR equipped with $4 \mathrm{~mm}$
CPMAS probe sample was run at $8000 \mathrm{kHz}$ ) was used to analyse the modification in structure of the virgin thin film composite reverse osmosis membrane and modified with $\quad 3000 \mathrm{mg} / \mathrm{L} \quad$ 1-Butyl-3-Methylimidazolium Chloride [BMIM] $[\mathrm{Cl}]$ ionic liquid.

Figure 8 shows the ${ }^{13} \mathrm{C}$ NMR spectra overlay of virgin thin film composite and membrane modified with $3000 \quad \mathrm{mg} / \mathrm{L} \quad$ 1-Butyl-3-Methylimidazolium Chloride [BMIM][Cl].

The origin of three new peaks at $21.6 \mathrm{ppm}, 26.6$ ppm and $118.4 \mathrm{ppm}$ in modified membrane can be attributed to weak interaction with $[\mathrm{BMIM}][\mathrm{Cl}]$. The

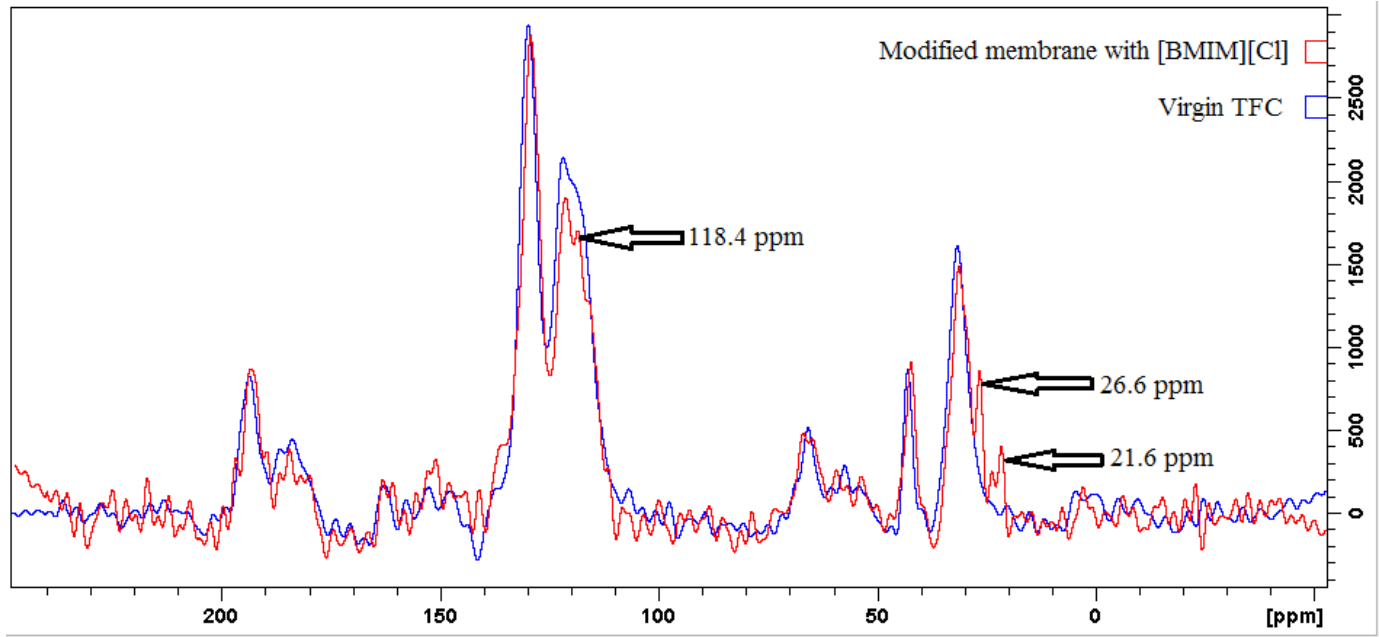

Figure 8. ${ }^{13} \mathrm{C}$ NMR spectra of virgin TFC and modified membrane with $3000 \mathrm{mg} / \mathrm{L}$ [BMIM][Cl] ionic liquid.

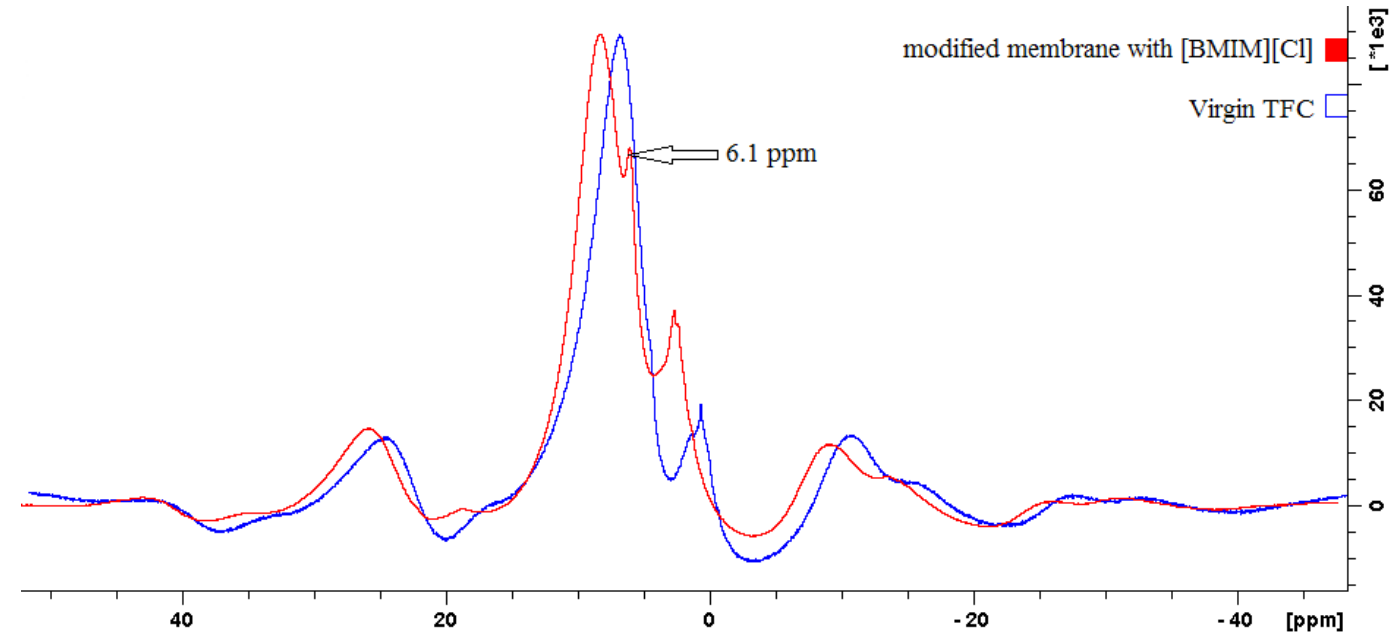

Figure 9. ${ }^{1} \mathrm{H}$ NMR spectra of virgin TFC and modified membrane with $3000 \mathrm{mg} / \mathrm{L}$ [BMIM][Cl] ionic liquid. 
peaks at $21.6 \mathrm{ppm}$ and $26.6 \mathrm{ppm}$ are related to the butyl chain of ionic liquid, where the associated peak at $118.4 \mathrm{ppm}$ can be assigned to aromatic imidazolium carbons. Shifting in the ppm value is due to the change of the chemical environment of carbons from a polymeric aromatic environment.

Figure 9 shows ${ }^{1} \mathrm{H}$ NMR overlay spectra of the same. The origin of the new associated peak at 6.1 $\mathrm{ppm}$ is related to aromatic imidazolium protons of the ionic liquid.

This clearly demonstrates that the polyamide layer has been modified by the ionic liquid through weak $\pi-\pi$ or cation- $\pi$ interactions.

Thus, the characterization of the membrane reveals the chemical, surface morphological and roughness changes and hydrophilic surface formation upon addition of ionic liquid into the polysulfone membrane matrix.

\section{CONCLUSION}

Different ionic liquids were used to modify the top polyamide layer of thin film composite reverse osmosis membranes. It was observed that the top polyamide layer of the thin film composite reverse osmosis membrane became thinner. Moreover, the contact angle of such modified membrane declined from $52.86^{\circ}$ to $43.12^{\circ}$, which demonstrated increased hydrophilicity. These factors contributed to an increase in water-flux. Divalent salt rejection of the modified membrane (3000 mg/L 1-Butyl-3-Methylimidazolium Chloride [BMIM][Cl] exposed for 2 hours after treatment with $2000 \mathrm{mg} / \mathrm{L}$ sodium hypochlorite for 2 hours) increased from $89.3 \%$ to $95.10 \%$ with an increase in water-flux from $2.08 \mathrm{LMH} / \mathrm{Bar}$ to 3.89 $\mathrm{LMH} / \mathrm{Bar}$. The performance increment was the highest with 1-Butyl-3-Methylimidazolium Chloride [BMIM] $[\mathrm{Cl}]$ as compared the other ionic liquids such as 1Butyl-3-Methylimidazolium Bromide [BMIM][Br] and 1-Methyl-3-Octylimidazolium Chloride [ $\mathrm{C}_{8} \mathrm{MIM}$ ] $[\mathrm{Cl}]$. The modified membrane had decreased surface roughness, with an increased surface area ratio. ATRFTIR spectra demonstrated the modification in the amide bond and prove the chemical modification of structure with ionic liquid treatment. ${ }^{13} \mathrm{C}$ - and ${ }^{1} \mathrm{H}-\mathrm{NMR}$ spectra demonstrated new peaks confirming the chemical structural modification with ionic liquid treatment. Scanning electron micrographs showed the modification in the morphology of the membrane with the treatment. Thus, the present paper demonstrates novel thin film composite reverse osmosis membrane with improved water flux, higher magnesium sulfate rejection and lower thickness of top polyamide layer upon ionic liquid treatment. It opens the possibility of future work in the area.

\section{ACKNOWLEDGEMENT}

CSIR-CSMCRI PRIS no PRIS 060/2017; Dated 19.04.2017. Authors acknowledge the funding support of Department of Science and Technology project DST/TSG/WM/2015/438 entitled "Value creation from solid waste: Discarded Reverse Osmosis Membrane Elements". Authors acknowledge Mr. Jayesh Chaudhary for SEM images, Mr. Ejaz for AFM images and Mr. Vinod Agrawal for ATR-FTIR spectra, Dr. Vinod Boricha for NMR analysis.

\section{REFERENCES}

Asano, T. (Ed.)., Wastewater Reclamation and Reuse: Water Quality Management Library. Vol. 10, CRC Press (1998).

Belfer, S., Purinson, Y., Fainshtein, R., Radcheno, Y., and Kedem, O., Surface modification of commercial composite polyamide reverse osmosis membranes. Journal of Membrane Science, 139(2), 175 - 181 (1998).

El-Saied, H., Basta, A. H., Barsoum, B. N., and Elberry, M. M., Cellulose membranes for reverse osmosis cellulose acetate membranes including a composite with polypropylene. Desalination, 159(2), 171-181 (2003).

Ghosh, A.K., Jeong, B.H., Huang, X., and Hoek, E. M., Impacts of reaction and curing conditions on polyamide composite reverse osmosis membrane properties. Journal of Membrane Science, 311(1), 34-45 (2008).

Gilron, J., Belfer, S., Vaisanen, P., and Nystrom, M., Effects of surface modification on antifouling and performance properties of reverse osmosis membranes. Desalination, 140(2), 167-179 (2001).

Glater J., The early history of reverse osmosis membrane development. Desalination, 117, 297-309 (1998).

Kulkarni, A., Mukherjee, D., and Gill, W. N., Flux enhancement by hydrophilization of thin film composite reverse osmosis membranes. Journal of Membrane Science, 114(1), 39-50 (1996).

Lua, J., Yana, F., and Texter, J., Advanced applications of Ionic Liquids in polymer science. Progress in Polymer Science, 34(5), 431-448 (2009).

Mohammad, A.W., Teow, Y.H., Ang, W.L., Chung, Y.T., Oatley-Radcliffe, D.L., and Hilal, N., Nanofiltration membranes review: Recent advances and future prospects. Desalination, 356, 226-254 (2015).

Morao, A. I. C., Alves, A.M.B., and, Geraldes, V., Concentration polarization in a reverse osmosis/ nanofiltration plate-and-frame membrane module. Journal of Membrane Science, 325(2), 580-591 (2008).

Petersen, R. J., Composite reverse osmosis and nanofiltration membranes. Journal of Membrane Science, 83(1), 81-150 (1993). 
Rangarajan, R., Desai, N.V., Daga, S.L., Joshi, S.V., Prakash Rao, A., Shah, V.J., Trivedi, J.J., Devmurari, C.V., Singh, P.S., Bapat, P.S., Raval, H.D., Jewrajka, S.K., Saha, N.K., Bhattacharya, A., Ray, P., Trivedi, G.S., Pathak, N., and Reddy, A.V.R., Thin film composite reverse osmosis membrane development and scale up at CSMCRI, Bhavnagar. Desalination, 282, 68-77 (2011).

Raval, H.D. and Gondaliya, M.D., A novel high-flux thin film composite reverse osmosis membrane modified by polysaccharide supramolecular assembly. Journal of Applied Polymer Science, 134(27), 1-7 (2017).

Raval, H.D. and Maiti, S., Ultra-low energy reverse osmosis with thermal energy recovery from photovoltaic panel cooling and TFC RO membrane modification. Desalination and Water Treatment, 57(1), 4303-4312 (2016).

Raval, H.D., Rana, P.S., and Maiti, S., A novel high-flux, thin-film composite reverse osmosis membrane modified by chitosan for advanced water treatment. RSC Advances, 5(9), 6687-6694 (2015).

Schmidt, C., Gluck, T., and Schmidt-Naake, G., Modification of Nafion Membranes by Impregnation with Ionic Liquids. Chem. Eng. Technol., 31(1), 13-22 (2008).
Swatloski, R. P., Spear, S. K., Holbrey, J. D., and Rogers, R. D., Dissolution of Cellulose with Ionic Liquids. Chem. Soc., 124(18), 4974-4975 (2002).

Tang, C. Y., She, Q., Lay, W. C., Wang, R., \& Fane, A. G., Coupled effects of internal concentration polarization and fouling on flux behavior of forward osmosis membranes during humic acid filtration. Journal of Membrane Science, 354(1-2), 123-133 (2010).

Wang, K.Y., Yang, Q., Chung, T.S., and Rajagopalan, R., Enhanced forward osmosis from chemically modified polybenzimidazole (PBI) nanofiltration hollow fiber membranes with a thin wall. Chem. Eng. Sci., 64(7), 1577-1584 (2009).

Wethern, M., and Katzaras, W., Reverse osmosis treatment of municipal sewage effluent for industrial reuse. Desalination, 102(1-3), 293-299 (1995).

Younos, T. and Tulou, K. E., Overview of desalination techniques. Journal of Contemporary Water Res. \& Ed. 132(1), 3-10 (2005).

Yung, L., Ma, H., Wang, X., Yoon, K., Wang, R., Hsiao, B. S., and Chu, B., Fabrication of thin-film nanofibrous composite membranes by interfacial polymerization using Ionic Liquids as additives. Journal of Membrane Science, 365(1), 52-58 (2010). 